\title{
New trends in content creation: changing responsibilities for librarians
}

\author{
Peter Johan Lor and Johannes J. Britz
}

Peter Johan Lor, Visiting Professor,University of Wisconsin-Milwaukee and Extraordinary Professor, University of Pretoria, South Africa. Email: lorpj@uwm.edu

Johannes J. Britz, Professor and Dean, School of Information Studies, University of Wisconsin, Milwaukee and Extraordinary Professor, University of Pretoria, South Africa.

Email: britz@sois.uwm.edu

\begin{abstract}
This paper addresses the changes in the role of librarians as information intermediaries due to the introduction of new forms of digital content brought about by modern information and communication technologies. The main focus is on the way in which these changes have affected the moral responsibilities of librarians. Six content trends are identified in support of this claim. These are: the growth in volume; amount of noise; sharing of content and information participation; personal space; collaboration and naive use. The ethical challenges of these six trends are discussed. Because of the unpredictability and uncontrollability of contemporary digital content, a case is made that the traditional model of retrospective responsibility, according to which responsibility is assigned based on causality, should be supplemented with a positive prospective model of responsibility according to which librarians also need to look 'forward' anticipating possible harmful impacts of modern ICTs. It is also argued, based on the open and interactive nature of new forms of content, that there should be a form of shared and distributed responsibility, which should include not only librarians, but also Internet service providers, library users, and software designers.
\end{abstract}

\section{Introduction}

Librarians are information intermediaries. From ancient civilizations onwards librarians have had the task of acquiring and organizing information-bearing artifacts (here referred to as documents), preserving them for future use, making them accessible, and facilitating their use by library clients. Technological advances have affected this role. When documents were scarce, the emphasis was on preservation. In medieval monasteries books were chained to the shelves so that they could not be removed from the library. Collections were small, so that organizing them did not pose a big problem. When printing made documents more plentiful, it became necessary for librarians to become more selective. Organization of collections became more complex and gained in importance as a professional task. The needs and desires of clients became more prominent. A greater awareness arose of the role of librarians in disseminating information, serving as intermediaries not only in scholarly communication but also in popular communication - information for democracy, for agricultural development, to combat HIVAIDS, etc. Thus modern librarians, at least in the period preceding the Internet, can be said to have moral responsibilities in respect of: 
- The creators or originators of documents: this entails a responsibility to ensure that documents reach their intended audience, as in Ranganathan's third law of library science: "Every book its reader" (Ranganathan 1931). This is a corollary of the notion of freedom of expression. A further responsibility is to respect the moral and economic rights of creators, for example the right to be acknowledged as the creator of a document, and the right, under certain conditions, to be compensated for its use, as in copyright.

- The collection of documents as a whole: libraries are institutions with a long-term perspective and collections are built up not only for immediate use but also to meet future needs. Hence, the importance of preservation. Furthermore, when documents are acquired, limited resources impose selectivity based on objective criteria.

- Current and future clients: respecting their autonomy as free agents, free to decide what to use and what not (which is a corollary of the notion of freedom of access to information), while attempting to identify and meet needs of which the clients may not be fully aware, and providing some guidance as to the authenticity and reliability of documents that are made accessible.

- The library as an institution: ensuring its survival and well-being.

Of course there are other moral responsibilities, for example those relating to the librarian's colleagues, which are discussed in the literature of library deontology, but these are not dealt with in this paper.

The relevance of these responsibilities to a conventional library, which assembles a physical collection of documents, appears self-evident. But is this still the case when the collection is partly or entirely virtual? In recent decades a steadily increasing proportion of the collection of many libraries has become digital. The library does not acquire physical documents, but negotiates electronic access to them. More significantly, beyond that, we have now reached the stage where librarians mediate access to large amounts of information that is not "collected" at all. Here we refer to digital content disseminated on the Internet. If libraries provide access to this content, do they have any ethical responsibilities in respect of it? This paper identifies some trends in the creation and use of digital content and explores the ethical implications of the responsibilities that librarians assume in respect of it.

\section{What are the trends?}

In this section six trends in the production and use of digital content are outlined.

\section{Volume and growth}

There has been much debate and speculation about the size of the Web. Based on standardized searches conducted regularly on a number of search engines, De Kunder (2010) estimated the indexed Web at 22.05 billion pages on January 17, 2010. This is almost double the January 2005 estimate of 11.5 billion "indexable pages" by Gulli and Signorini (2005). But in view of disputes between search engine giants Yahoo and Google about how many pages they index, Markoff (2005) observed: "How big is the World Wide Web? Many Internet engineers consider that query one of those imponderable philosophical questions, like how many angels 
can dance on the head of a pin." Nevertheless, there is no doubt that the amount of information on offer is enormous and growing rapidly.

A distinction is made between the "surface Web" and the "deep Web". The latter refers to public content that is only accessible through direct database queries, as distinct from the content retrieved by search engines such as Google. Bergman (2001) estimated that the "deep Web" is about 500 times greater than the indexible or surface Web.

Even if the figures may be out by an order of magnitude, the amount of information is staggering. What may not be as evident is the amount of information that is lost. According to DomainTools (2009) on July 29, 2009 there were 110,562,560 active domains and 367,916,425 deleted domains. Over a period of 24 hours 113,559 domains were added and 74,392 domains expired. The estimates by DomainTools suggest that for every active domain there are at least three deleted domains. What happens to the information carried in the deleted domains? Undoubtedly, most of it is permanently lost. Does anyone have a responsibility for preserving it, and if so, do librarians have a share in that responsibility?

The preservation challenge is compounded by the growth of ubiquitous and mobile computing and new social networking systems such as Twitter, which are blurring the distinction between the Internet as a source of content and as a common carrier for private messaging. During the protests following the 2009 elections in Iran, much of the information came from Iranians in the streets reporting directly to the world via Twitter (K. Anderson 2009). Do libraries have a responsibility to preserve the messages relating to those events as historical archives, or will they stay only within the Twitter servers until they are deleted as space is needed or those Iranian users close their Twitter accounts?

\section{Noise}

The Web includes a very large quantity - a "long tail", to use the terminology popularized by Chris Anderson (2006) - of trivial and personal material. This comprises noncommercial, obscure, esoteric, trivial, ephemeral and idiosyncratic content, which may just be of interest to a very small number of people who are scattered all over the world. The much smaller quantity of more generally useful and valuable material is not easy to separate out from this huge amount of content. For a user working in a poor country, using a dial-up line or a metered ADSL (Asymmetric Digital Subscriber Line) allowing a limited number of megabytes per month, this cornucopia can be a serious impediment. To illustrate: one of the authors worked on this paper while in Sedgefield, a small town within the municipality of Knysna in the Western Cape Province of South Africa. The municipality had taken the enlightened step of providing free WiFi Internet to its residents - but the free Wi-Fi was limited to $35 \mathrm{MB}$ a week, which are used up in no time. Additional bandwidth could be purchased at around US\$12 for $500 \mathrm{MB}$, which is very expensive in comparison to the cost of bandwidth available to home users in Western Europe and North America. In Africa some universities have less bandwidth than such a home user.

This raises questions about the use of limited library resources for the downloading of what may be labeled as trivial material, for example, music and videos. In the USA the library profession devotes considerable energy and resources to ensuring that sexually explicit material is not censored by conservative-minded citizens, invoking the rights enshrined in the First Amendment to the U.S. Constitution. Seen from an African perspective, where limited library 
bandwidth must be reserved for "serious" educational and research purposes, this is a non-issue. A policy restricting access to popular or "trivial" content such as music and video downloads or to pornographic websites could be labeled as censorship or wise use of limited resources, depending on the context. It can be argued that the library has a responsibility to ensure the most effective use of the institution's resources in the interests of all. But who decides what is popular, trivial, or pornographic?

\section{Participation}

In Western Antiquity and in the Middle Ages, individuals (writers and copyists) communicated their content to small audiences: one communicating to few. After the invention of printing, intermediaries such as printers and publishers emerged. Content production became industrialized and reached ever larger audiences: one to many. The coming of the Internet has wrought a fundamental and disruptive change: now everybody can create and communicate content: many to many. Video-sharing sites such as YouTube have grown enormously and are heavily used (Rainie 2008). In August 2006, YouTube was hosting about 6.1 million videos (requiring about 45 terabytes of storage space) (Gomes 2006). YouTube's website claimed on December 15, 2009 that "[p]eople are watching hundreds of millions of videos a day on YouTube and uploading hundreds of thousands of videos daily. In fact, every minute 20 hours of video is uploaded to YouTube."

The new technology enables creativity and free expression (Uricchio 2008). In the 2008 U.S. Presidential elections, the voters were no longer reliant only on formal, commercial mass media. Everybody could add to the debate. Satirical video "mashing" and parody are important new forms of expression, as is evident if one searches on YouTube using the search terms "Hillary Clinton" (73,200 hits in July 2009) or "Barack Obama" (206,000 hits). Another example is fan fiction - fiction written about fictional characters or settings written by admirers of the authors that created them (Wikipedia 2008), for example, stories about Harry Potter written not by J. K. Rowling but by Harry Potter fans.

According to Peter Nicholson (2006) we live in a time that is characterized by two major trends that are affecting intellectual authority in our society. On the one hand, people distrust the experts. The authority of doctors, priests and professors is no longer unchallenged. People want to find out and decide for themselves. On the other hand, we face an unprecedented information explosion made possible by modern information and communications technologies (ICTs). The information in circulation is disorganized and of varying quality. Intermediaries are needed to help evaluate and organize it -- or are they? New approaches to authority are taking shape. Discussing this, Jensen (2007) refers to the authority conferred by Google's search algorithm, which is based mainly on "applause and popularity", and to group-participation models in which "engaged participation helps filter out crap", while Lankes (2008) foresees a shift in the basis of credibility, from authority to reliability, where users determine credibility themselves on the basis of multiple sources.

This raises questions about the authenticity and reliability of what library clients find on the Internet using facilities provided by the library. Does the library have any responsibility for advising or guiding clients? Which clients? Should such guidance take the form of "surfing advisories" or "site advisories", analogous to the travel advisories issued by the US Department of State and other ministries of foreign affairs? Should emphasis rather be placed on inculcating 
a more general information literacy which comprises a healthy skepticism in respect of anything found on a computer screen as well as on a printed page?

\section{Personal space}

People are using the Web for personal documents and (semi) private social interaction: blogs in the place of diaries, Flickr or Picasa Web instead of photo albums, MySpace and Facebook profiles and Twitter instead of face-to-face interaction. A U.S. survey by the Pew Internet \& American Life Project showed that $64 \%$ of online teenagers (12-17) were involved in one or other kind of content creation. $35 \%$ of teenage girls blogged, and $54 \%$ posted photos. Boys blogged less and posted photos less than girls, but posted more videos (Lenhart et al. 2007). More recent figures available from the Pew Internet and American Life Project indicate that $73 \%$ of teens use social network sites (Rainie 2009). The social networking sites have enabled the general dissemination of material which formerly would have been confided to private dairies or expressed in letters to close family or friends. It has been reported that some employers are beginning to seek information about job applicants on social networking sites (Brandenburg 2008). Thus their appointment decisions may be influenced by material posted earlier by candidates as a joke or in a fleeting gesture of bravado, but which has remained accessible on the Web. The dangers of the resulting interactions are illustrated by the case of Megan Meier, a thirteen-year-old American teenager who committed suicide in 2007 after an exchange of hostile messages with a person she thought was a teenage boy, whom she had met on MySpace (Collins 2008).

Should clients be using library-enabled Internet to access social networking sites? If so, do librarians have any responsibilities to prevent potential harm?

\section{Collaboration}

The Web is an interactive space, and collaboration is an essential part of the Web ethic. Information no longer flows only in one direction, from creator to consumer. Under every photo on Flickr or Picasa Web, the user is invited to make comments. Links are made with social bookmarking sites such as Delicious. Consumers are creators too. This is also illustrated by the volunteered reviews that one can read while shopping online for anything from digital cameras to holiday accommodation, and by the websites and blogs providing advice on topics ranging from bird identification to health issues and pesky software problems.

Tagging has emerged as a major collaborative activity, which is likely to have a pervasive impact (Rainie 2007). The tagging of items using systems such as Flickr creates "folksonomies", taxonomies built up (bottom-up) by the "indexing" efforts of hundreds and thousands of visitors. Folksonomies have been hailed as offering an alternative to "top-down" classifications and hierarchies (Terdiman 2005). However, how reliable are such tags and how much noise is generated? Anyone who has looked at a Google Earth view of a city or neighborhood with which he or she is familiar will have noticed that many of the tags and images added by users have been incorrectly positioned. A library client relying on such information could end up in serious difficulties if, for example, hiking a wilderness trail. Again, users need to be "street savvy" in their use of such sites. Do librarians have a responsibility to warn, advise, and teach? 
The standard-bearer of the collaborative approach is the Wikipedia. Critics of Wikipedia point out that it is easy for any Web surfer to add incorrect information to Wikipedia entries whether through ignorance or malice. The supporters of Wikipedia counter that its openness has made it possible to cover many more topics in greater detail and in many more languages than can be found in conventional encyclopedias, and that high usage of the system ensures that any errors are noticed and corrected very quickly. Maier (2007) has pointed out that "Wikipedia's long-lasting success is based not on anarchy, but rather on a rigorous hierarchy. Every article is strictly scrutinized before it is published and ultimately revised by the 'last editor,' who resides at the top of the hierarchy. Contributors have to qualify over a certain period of time, and individual pages can be blocked if something goes wrong." A vigilant community keeps malicious edits in check. Davidson (2007) has pointed out that "Wikipedia is not just an encyclopedia. It is a knowledge community, uniting anonymous readers all over the world who edit and correct grammar, style, interpretations, and facts. It is a community devoted to a common good - the life of the intellect." The credibility of Wikipedia has been examined by various authors, e.g., Chesney (2006). Some teachers and college professors discourage the use of Wikipedia or impose a quota on the number of times it may be referred to in a term paper - an approach discussed and criticized by Maehre (2009) - while other teachers have used it as a tool for teaching critical thinking (Harouni 2009). Here again issues of responsibility emerge: censorship, the provision of guidance and the role of general information literacy.

Apart from the issue of authority and reliability, the trend to Internet-based participation and collaboration also raises issues of the attribution and recognition of authorship. In modern scholarship a high value is placed on the priority of discoveries, concepts, and ideas. Most academe-based scholars publish to earn recognition by their peers, rather than money. This system requires scrupulous recognition of the original contributions of others. Deliberate failure to do this is considered to be plagiarism, which among scholars is considered a cardinal sin. As a counter-trend, the collaborative Web ethic plays down the importance of original contributions by individuals. In addition, modern information technology makes it easy to compile a new document by cutting and pasting pieces from Web-based resources. It is no coincidence that plagiarism has become a major problem at colleges and universities. What responsibility do librarians have in combating plagiarism? Should a librarian who, in providing assistance to a library client, becomes aware of an instance of plagiarism report this to a student's professor or thesis committee, or should the duty of client confidentiality outweigh this?

In this connection the open access movement should also be mentioned. We emphasize that there is no contradiction between the availability of documents on open access and the proper attribution and recognition of authorship. These are covered by normal academic usage and can additionally be dealt with by means of systems such as CopyLeft and the Creative Commons license. The question that does arise is whether, in addition to undertaking practical measures to ensure availability of open access material (Bailey 2008), librarians have a moral responsibility to promote open access among their clients. Closely related to the scholarly open access movement is the open learning (or open educational resources) movement, which promotes open access to educational resources (Atkins, Brown \& Hammond 2007). What role should librarians play in this? The emergence of virtual research environments (VREs) (Myhill, Shoebridge, \& Snook 2009), where scholars work in virtual research groups using Web-based facilities for international research collaboration (Keraminiyage, Amaratunga, \& Haigh 2009), 
also requires the attention of librarians. What role should librarians play in supporting or promoting this form of scholarship?

Naïve use

The simple search engine interface has become ubiquitous. The user merely has to type a word or two in a box and click, upon which thousands of hits appear. Why bother with Boolean searches on defined fields? Instead of logging on to a bibliographic database and doing a systematic literature search, students (and many professors) use Google. Instead of using articles from refereed journals, they use Wikipedia. Curiosity and serendipity play a big role in searching for information. This is more fun, in a time when fun is important. However, many users assume that everything of any significance is (a) available on the Web and (b) can be found using popular search engines such as Google and Yahoo. They are wrong on both counts. A large proportion of all scholarly literature is still available only in print. And search engines have flaws and biases of which most users are unaware. Furthermore, many users are unable to evaluate the authenticity, reliability and accuracy of the search results (Laurence 2000; Herring 2008; Badke 2009). Apart from offering programs of information literacy, do librarians have a moral responsibility to provide (unsolicited) guidance to library clients to "protect" them against the consequences of their assumptions?

\section{Implications}

We turn now to the implications of the six content trends for the role and ethical responsibilities of librarians. Before the Web 2.0 phenomena outlined here, librarians were already confronted with a very significant increase in the volume of content produced. This attracted a lot of attention and generated metaphors such as information overload, information flood and information deluge. It is now clear that the volume of information is merely the most obvious dimension of a more complex phenomenon. Along with the ballooning volume, there is a huge increase in the diversity and quality of what is produced, a consequence of the striking increase in the numbers and roles of those producing content. All this is made possible by the new technology, which continues to develop rapidly and unpredictably.

Important and impressive as these trends are, it is simplistic to think that the role of the librarian is mainly affected by the volume and diversity of the content. We suggest that, more fundamentally, it is the unpredictability and uncontrollability of the content entering libraries that requires a major rethink of the role of librarians. Traditionally librarians were gatekeepers. They controlled the flow of content entering the library (through purchases, exchanges, gifts, and inter-library loans) applying criteria of quality, relevance, affordability, etc. They were not expected to be familiar with the detailed contents of every item in the library. However, they applied professionally approved and disseminated selection criteria (as discussed in standard library science texts of earlier generations such as Drury (1930), Carter and Bonk (1959), and Broadus (1973) to the purchase of books, series, periodical titles, and standing orders. They could also rely on the track record and reputations of the established content producers such as publishers. Thus librarians could reasonably be expected to have a fair idea of what was being added to the collection. Selection of content, implying a degree of control, was one of the core 
professional functions of the librarian, featuring in the core curricula for professional qualifications (Nasri 1972).

This changed as the concept of a library collection was expanded over the past several decades (Lee 2000). In an essay on the education of librarians, Michael Gorman (2009, 152-3) has described this phenomenon as follows:

Libraries today have a variety of 'collections'. The most obvious is the collection of tangible objects that the library owns and houses. There is also the universe of such collections owned by other libraries to which the library has access by means of union catalogues, inter-library lending programs, document delivery processes, etc. Then there are the intangible objects (electronic documents and resources) for which the library pays (by subscription or otherwise). Lastly there is the universe of intangible documents that are available to the library and its users by means of the computer access provided by the library.

Gorman goes on to identify the selection of the first and third of the above components of the library "collection" (the tangible and intangible documents acquired by the library) as a "primary professional activity" $(2009,153)$. Although he deals with it under the heading of "selection", Gorman does not say whether the librarian has any responsibility in respect of the fourth component, the documents to which the library provides computer access. In our view, librarians were able to exercise their professional function of selection as library collections first expanded through resource-sharing, then through licensing of on-line materials which did not physically enter the library but to which the librarian negotiated access. However, a critical point was reached when libraries set up workstations with Internet connections for use by their patrons. By doing this, they expanded their collections by orders of magnitude. At the same time, the content to which users were able to gain access in the library became unpredictable.

This loss of control of the library's content undermines what was in the past a major dimension of the librarian's professional responsibility. Could this be seen as jeopardizing the professional role of the librarian? From the responsibility perspective we have to ask what the implications are for the moral responsibility of the librarian.

\section{Moral responsibility: a new way of thinking for libraries}

The introduction of modern ICTs, in particular new social media, not only changed the existing order, but also challenged the traditional responsibilities associated with the roles of librarians as collectors, disseminators and preservers of information on behalf of their users. As we have pointed out, they no longer operate in what was for them a well known and controlled environment where their different responsibilities were related to their assigned duties. They are assigned an additional role - a role as information flow facilitators, or in legal terms - the role of a common carrier (Lipinski 2002). In the legal jargon of the United States, Internet Service Providers are referred to as common carriers. This is based on their function whereby they provide an information infrastructure or platform facilitating the flow of digital information via networks. In a certain sense libraries are fulfilling a similar function now by providing access to the Internet with little or no control over the kinds of information that is accessed or used by library patrons. This new role, due to the development of new ICTs, has created new conditions that require a different response from librarians with regard to their role and moral 
responsibilities. Indeed, Jonas $(1984,31)$ has asserted that "[m]odern technology has introduced actions of such novel scale, objects and consequences that the framework of former ethics can no longer contain them...."

In discussing these changing conditions we take as our starting point that librarians as moral agents should have the ability to make moral judgments based on clear moral values. As such, our focus is therefore on the question how the new forms of content and the librarian's newly assigned role impact and change the traditional understanding of their moral responsibilities. This is a topic not well covered in the current literature and for us it is an imperative to engage in the ongoing conceptual analysis of the impact of new media on the moral responsibilities of librarians.

\section{Understanding moral responsibility}

In doing so it is important to clarify what is meant by responsibility and in particular moral responsibility - a concept that was first introduced by Max Weber, who used it in the context of political responsibility (Speirs1994). Etymologically the word originates from the Latin word respondeo, which relates not only to accountability but also to blame and/or punishment. Two conditions for responsibility can be distinguished. The first is a causal condition according to which a person's actions cause harm. The second is a mental condition where a person must have intended or willed the harm (Nissembaum 1994). Moral responsibility protects a broad realm of human interest and is based on a set of core values to which a particular society or group of people adhere. Finding a set of core values shared by librarians around the world is of course a challenging if not impossible task. We agree with Habermas $(1993,57)$ that such a common set of core values can only be reached through a communicative, inter-subjective ethical approach. Based on the codes of ethics of a number of international and national library associations which we have consulted [1], we propose the following list of shared core values that can be used to guide their moral decision making:

- the recognition of the right of equitable access to information,

- the recognition of the right to freedom of expression,

- the respect for and protection of the right to privacy and confidentiality of library users,

- professional neutrality,

- the recognition and the respect for the right to ownership of information and the use of intellectual property

As indicated, these values are mostly translated in the form of professional codes of ethics providing guidance on how librarians should understand their moral responsibilities as information intermediaries. It is, however, important to note that these codes in most cases cannot be enforced nor do they have any regulatory mandate. They are mostly advisory, helping to create an ethically sensitive environment and their "value comes in great part through symbolism" (Buchanan \& Henderson 2009,16). While this fundamental understanding of responsibility can cross borders, the attribution of responsibility can become more complex and confusing when there is a clash of these norms. For example, a potential clash exists between freedom of speech and defamation, while another potential clash exists between a library users' right to privacy versus the social responsibility of a librarian. 
Although these moral values did not change with the introduction of modern ICTs, in particular the Internet, the interpretation thereof and levels of applications have. We argue that the moral responsibilities that have been suggested in respect of the six trends can be roughly divided into two groups or levels. At what one might call the micro level are the largely traditional professional responsibilities of librarians in respect of creators, collections, clients, and the library as an institution, as outlined in the introduction. As pointed out these responsibilities are mostly articulated in codes of ethics and relate to the interactions of librarians with individuals, with individual cases such as banned books, or with categories of these. Today these responsibilities are no different in essence from those of librarians a few decades ago. But in the age of the Internet they have acquired an added edge of sophistication and complexity and have opened up a new philosophical debate reflecting on these new moral challenges (Jonas 1984; Ladd 1991). For example, in the past minors were confined to the children and teenage sections of public library collections, which was intended ensure that they were not exposed to materials that the community did not consider suitable for them. This raised major ethical issues that have not gone away. They now have an added, technological dimension, for the Web browsers installed on library computers do not know the distinctions between children's, teen, and adult literature. If the librarian is held to have a duty of care for minors (in loco parentis) then the vexed issue of filtering arises. Other examples of issues at the micro level are: preventing harm by providing guidance to clients ("surfing advisories"), the promotion of information literacy, and combating plagiarism.

At the macro level, on the other hand, we need to identify the changing social responsibilities of librarians in a larger context, where the library as an institution takes its place in the systems of scholarly and popular communication, alongside authors, publishers, media, distributors, institutional repositories, and the emerging systems of open access and open learning. This goes beyond the professional interaction with library patrons. Here we need to consider the moral responsibility of librarians in such matters as long-term preservation of documents, freedom of information, equitable access to information (including issues of copyright limitations and exceptions in respect of digital resources, open access and open learning), the support of cyber-scholarship and digital curation.

\section{A prospective and distributed model of responsibility?}

The introduction of the new media and, in particular the Internet, has made the library a more complex entity, with many stakeholders and role players, and holding many roles and responsibilities. In the discussion and assigning of moral responsibility to the librarian, this complexity must be considered.

In the first place we need to reconsider what is referred to in moral philosophy as the retrospective model of moral responsibility, according to which responsibility is assigned based on causality - in other words a person's actions must have caused the harm, it must have been done intentionally, and the person must have understood the consequences of his/her actions (Birsch 2004). As a causal responsibility it looks 'backward' as it were, to determine through which action and by whom a particular outcome was caused. In the context of our discussion the attribution of responsibility is made on the moral judgment that failure by a librarian to fulfill his 
professional duties has led to an untoward event or outcome. As such, it presupposes an epistemic condition according to which the librarian has the appropriate level of professional knowledge to do the work. For example, a cataloger in a library will be held responsible if a patron cannot find a particular book in the library due to the assigning of incorrect subject headings.

The development and introduction of modern ICT has 'weakened' this causality and it has become much more difficult to assign responsibility in only a retrospective way. Librarians have much less control over the processing and distribution of information. How can one blame a librarian for the nebulous kinds of information that are now available on the Internet or for the lack of good indexing and inappropriate information retrieval methods applied by Internet search engines? It has become nearly impossible to identify which intentional actions of a librarian have caused what harm. De Villiers $(2002,16-21)$ refers to this shift as the growing 'responsibility gap'. It is this question that has led philosophers such as Ladd (1991) and Jonas (1984) to introduce the notion of prospective responsibility - according to which individuals (including librarians) have a moral obligation to 'look forward' and prevent harm by means of different measures (Vedder 2001). For example, it may be argued that librarians, based on their social responsibility, need to install filter software on the computers that are used by children in a library - in anticipation that they might gain access to harmful information. A clear understanding and specific assigning of prospective responsibility to librarians also justifies the more accurate assignment of retrospective responsibility to them. For example, if librarians neglect to install filter software or decide not to they will have to assume their retrospective moral responsibility for not doing so.

We argue therefore that it has become necessary for librarians to supplement the traditional notion of retrospective responsibility by a positive prospective responsibility. Librarians need to look 'forward', anticipating possible outcomes caused by the use of modern ICT. They need to be prepared to take some 'moral risks' in accepting responsibility for the way in which patrons might use the Internet in a library without exactly knowing what the outcomes might be.

The open and interactive nature of new media also poses the question whether it should be an individual responsibility or whether the emphasis should move towards other professional role players and even the community at large - in other words - the library users? In this context Ess $(2009,17)$ asks an important question, namely to what extent we should rather look at a moral responsibility as a distributed responsibility. Thereby we will not hold the librarian alone responsible for morally acceptable actions in a library. It will have become a shared responsibility across the networks of moral agents including users, designers, and Internet Service Providers. In this sense one can even talk of becoming co-responsible and coaccountable. This is based on Bonhoeffer's (1986) social theory of responsibility according to which a person becomes a co-responsible person under certain circumstances. An example would be the case of protection as with a parent or a teacher, or in this case a children's librarian. A children's librarian always has a moral responsibility towards children. This can be seen as a relationship of implied responsibility that is determined inter alia by the level of control that the children's librarian (and similarly, the parents and for example, the software company producing the filter software) has over the medium of communication as well as the place of communication in the library. 


\section{Conclusion}

We have argued that the role of librarians as information intermediaries has been affected by the introduction of modern ICTs. Not only did the organization and management of library collections (now mostly virtual) become more complex, but new challenges have arisen with regard to the moral responsibilities of librarians as information intermediaries. This is not only because of the increase in volume but also due to the unpredictability and uncontrollability of the content.

Because of this unpredictability and uncontrollability of the content we have made a case that the traditional model of retrospective responsibility, according to which responsibility is assigned based on causality, should be supplemented by a positive prospective model of responsibility according to which librarians also need to look 'forward', anticipating possible harmful outcomes arising from the digital content disseminated by modern ICTs. We also argued, based on the open and interactive nature of new content, that there should be a shared and distributed form of responsibility, including librarians, Internet service providers, library users, and software designers.

\section{Acknowledgements}

We are indebted to Professor William Uricchio, whose 2008 presentation at the Royal Netherlands Academy of Sciences has informed our understanding of some key trends in digital media and to Jess Vargas Robinson for assisting with literature searching, the checking and updating of references, and editing.

\section{Note}

1. These include the American Library Association Code of ethics, Canadian Library Association Code of Ethics, The Statement on Professional Ethics by The Australian Library and Information Association (ALIA) and The Chartered Institute of Library and Information's Code of Professional Conduct in Great Britain.

\section{References}

Anderson, C. 2006. The long tail: How endless choice is creating unlimited demand. London: Random House.

Anderson, K. 2009. Twitter delays maintenance to support Iran protests. PDA: thedigitalcontentblog of The Guardian, posted June 16, 2009, http://www.guardian.co.uk/media/pda/2009/jun/16/twitter-middleeast [accessed January 4, 2009]

Atkins, D. E., J. S. Brown, and A. L. Hammond. 2007. A review of the Open Educational Resources (OER) movement: Achievements, challenges, and new opportunities. Report to The William and Flora Hewlett Foundation. San Francisco, CA: Creative common. http://www.oerderves.org/wp-content/uploads/2007/03/a-review-of-the-open-educationalresources-oer-movement_final.pdf [accessed 15 December 2009] 
Badke, W. 2009. How we failed the net generation. Online 33(4), 47-49. Professional Development Collection, EBSCOhost.

Bailey, CW. 2008. Open access and libraries. Collection Management 32(3\&4), 351-383. DOI: 10.1300/J105v32n03_07

Bergman, MK. 2001. White Paper: The Deep Web: Surfacing Hidden Value. The Journal of Electronic Publishing 7(1). DOI: http://dx.doi.org/10.3998/3336451.0007.104. Available http://quod.lib.umich.edu/cgi/t/text/textidx? $=$ jep; $v$ iew=text;rgn=main;idno=3336451.0007.104 [accessed 26 December 2009]

Birsch, D. 2004. Moral responsibility for harm caused by computer system failures. Ethics and Information Technology 6(4): 233-245. DOI: 10.1007/s10676-005-5609-5.

Bonhoeffer, D. 1986. Ethics. New York: Collier Books.

Brandenburg, C. 2008. The newest way to screen job applicants: A social networker's nightmare. Federal Communications Law Journal 60(3), 597-626. Retrieved from ABI/INFORM Global. Document ID: 1536934351 [accessed 26 December 26, 2009]

Broadus, R. N. 1973 Selecting materials for libraries. New York: H.W. Wilson Co.

Buchanan, EA., and KA. Henderson. 2009. Case studies in library an information science ethics. Jefferson, N.C.: McFarland \& Co.

Carter, MD. and WJ. Bonk. 1959. Building library collections. New York: Scarecrow Press.

Chesney, T. An empirical examination of Wikipedia's credibility. First Monday 11(11November 6, 2006). http://firstmonday.org/article/view/1413/1331

Collins, L. 2008. Friend Game: Behind the online hoax that led to a girl's suicide. New Yorker, January 1.

Davidson, CN. 2007. We can't ignore the influence of digital technologies. The Education Digest 73(1), 15-18. OmniFile Full Text Mega, WilsonWeb: http://vnweb.hwwilsonweb.com/hww/jumpstart.jhtml?recid=0bc05f7a67b1790e19db792 9980c435f7035d5acc2200a678e 038dc7f4b2d3e3214d654df235ae1b\&fmt $=$ P [accessed 26 December 2009]

De Kunder, M. 2010. The size of the World Wide Web. http://www.worldwidewebsize.com/ [accessed January 2010]

De Villiers, E. 2002. Who will bear moral responsibility? Communicatio: South African Journal for Communication Theory and Research 28(1): 16-21. URL: http://www.informaworld.com/10.1080/02500160208537953

DomainTools. 2009. Domain Counts \& Internet Statistics. http://www.domaintools.com/internetstatistics/ [accessed 26 December 2009]

Drury, FKW. 1930. Book selection. Chicago: American Library Association.

Ess, C. 2009. Digital media ethics. Cambridge, U.K.: Polity Press.

Gomes, L. 2006. Will all of us get our 15 minutes on a YouTube video? Wall Street Journal, August 31. http://online.wsj.com/public/article/SB1156892981680489045wWyrSwyn6RfVfz9NwLk774VUWc_20070829.html [accessed 26 December 2009]

Gorman, M. 2009. A unified approach to the teaching of library studies. In The politics of libraries: Challenges and realities, ed. K. Smith, 149-158. Oxford: Chandos.

Gulli, A., and A. Signorini. 2005. The Indexable Web is more than 11.5 billion pages. http://jmm.aaa.net.au/articles/15080.htm [accessed 26 December 2009]

Habermas, J. 1993. Moral consciousness and communicative action. Cambridge, MA: MIT Press. 
Harouni, H. 2009. High school research and critical literacy: Social studies with and despite Wikipedia. Harvard Educational Review 79(3): 473-494. http://hepg.metapress.com/content/dxxt414m1224j7v1 [accessed 15 December 2009]

Herring, MY. 2008. Fool's gold: Why the Internet is no substitute for a library. Journal of Library Administration 47(1): 29-53. Academic Search Complete, EBSCOhost. DOI: 10.1080/01930820802110605.

Jensen, M. 2007. The new metrics of scholarly authority. Chronicle of Higher Education, June 15. URL: http://chronicle.com/article/The-New-Metrics-of-Scholarl/5449/ [accessed 4 January 2009]

Jonas, H. 1984. The imperative of responsibility: In search of an ethics for the technological age. Chicago \& London: The University of Chicago Press.

Keraminiyage, K., D. Amaratunga, and R. Haigh. 2009. Achieving success in collaborative research: The role of virtual research environments. Journal of Information Technology in Construction 14, Special Issue Technology Strategies for Collaborative Working: 5969. URL: http://itcon.org/data/works/att/2009 07.content.05004.pdf

Ladd, J. 1991. Computers and moral responsibility: A framework for an ethical analysis. In Computerization and controversy: Value conflicts and social science, ed. C. E. M. Dunlop and R. Kling, 664-675. Boston: Academic Press.

Lankes, RD. 2008. Credibility on the Internet shifting from authority to reliability. Journal of Documentation 64(5): 667-686. DOI: 10.1108/00220410810899709. URL: http://quartz.syr.edu/rdlankes/Publications/Journals/credibilityontheinternet.pdf

Laurence, H. 2000. Introduction to Academic research on the Internet: Options for scholars and libraries, ed. H. Laurence and W. Miller, 1-8. New York: Haworth Information Press. Accessed via Google Books: http://books.google.com/

Lee, H-L. 2000. What is a collection? JASIS 51(12): 1106-1113.

Lenhart, A., M. Madden, AR. Macgill, and A. Smith. 2007. Teens and social media: the use of social media gains a greater foothold in teen life as they embrace the conversational nature of interactive online media. Washington, D.C.: PEW Internet \& American Life Project. http://www.pewinternet.org/PPF/r/230/report display.asp [accessed 26 December 2009]

Lipinski, TA. 2002. To speak or not to speak: Developing legal standards for anonymous speech on the Internet. Informing Science 5(3): 95-111. http://www.inform.nu/Articles/Vo15/v5n3p095-111.pdf

Maehre, J. 2009. What it means to ban Wikipedia. College Teaching 57(4): 229-236. Academic Search Complete, EBSCOhost [accessed 17 December 2009]

Maier, M. 2007. Journalism without journalists: Vision or caricature? Discussion paper \#D-40 presented at the Joan Shorenstein Center on the Press, Politics, and Public Policy, November. http://www.hks.harvard.edu/presspol/publications/papers/discussion_papers/d40_maier.p df [accessed December 15, 2009]

Markoff, J. 2005. In Silicon Valley, a debate over the size of the Web. New York Times, August 15. http://www.nytimes.com/2005/08/15/technology/15search.html [accessed 26 December 2009]

Myhill, M., M. Shoebridge, and L. Snook. 2009. Virtual research environments - a Web 2.0 cookbook? Library Hi Tech 27(2): 228-238. DOI: 10.1108/07378830910968182 
Nasri, WZ. 1972. Education in library and information science. In Encyclopedia of library and information science, ed. A. Kent \& H. Lancour, vol. 7, 416-465. New York: Marcel Dekker.

Nicholson, PJ. 2006. The changing role of intellectual authority. ARL 247: 1-5. http://www.arl.org/arldocs/resources/pubs/mmproceedings/148/nicholson.pdf [accessed 26 December 2009]

Nissenbaum, H. 1994. Computing and accountability. Communications of the ACM 37(1): 7280.

Rainie, L. 2007. Tagging. PEW Internet \& American Life Project. http://www.pewinternet.org/Reports/2007/Tagging/Report/Interview.aspx?r=1 [accessed 18 January 2010]

Rainie, L. 2008. Increased use of video-sharing sites. PEW Internet \& American Life Project. http://www.pewinternet.org/PPF/r/232/report_display.asp [accessed 26 December 2009]

Rainie, L. 2009. Networked Learners. Pew Research Center's Internet \& American Life Project. http://www.pewinternet.org/Presentations/2009/52-Networked-Learners.aspx [accessed 18 January 2010]

Ranganathan, SR. 1931. The five laws of library science. Madras: Madras Library Association; London: Edward Goldston.

Speirs, R. 1994. Introduction. In Political Writings. Cambridge texts in the history of political thought, ed. M. Weber, P. Lassman, and R. Speirs, x-xxx. Cambridge, U.K.: Cambridge University Press.

Strawson, G. 2002. The impossibility of moral responsibility. In Reason and responsibility: Readings in some basicproblems of philosophy, ed. J. Feinberg and R. Shafer-Landau, 513-522. 11th edition. Wadsworth: Canada.

Terdiman, D. 2005. Folksonomies tap people power. Wired. http://www.wired.com/science/discoveries/news/2005/02/66456 [accessed 26 December 2009]

Uricchio, WC. 2008. New media literacies - the long view. Unpublished paper delivered at the Conference on Literacy in the Age of the New Media, March 28, 2008, at Koninklijke Nederlandse Academie van Wetenschappen, Amsterdam.

Vedder, A. 2001. Accountability of Internet access and service providers - Strict liability entering ethics? Ethics and Information Technology 3(1): 67-74.

Wikipedia. 2008. Fan fiction. http://en.wikipedia.org/wiki/Fan_fiction [accessed 26 December 2009]

YouTube. 2009. YouTube fact sheet. http://www.youtube.com/t/fact sheet [accessed 15 December 2009]

Editorial history:

Received 8 March 2010;

Accepted 24 May 2010. 